\title{
Nonlinear Finite Element Modeling of Red Meranti Compression at an Angle to the Grain
}

\author{
Yosafat A. Pranata ${ }^{1} \&$ Bambang Suryoatmono $^{2}$ \\ ${ }^{1}$ Department of Civil Engineering, Maranatha Christian University, Indonesia \\ Jalan Suria Sumantri 65, Bandung, 40164, Indonesia \\ ${ }^{2}$ Department of Civil Engineering, Parahyangan Catholic University, Indonesia \\ Jalan Ciumbuleuit 94, Bandung, 40141, Indonesia \\ Email: yosafat.ap@gmail.com
}

\begin{abstract}
In an orthotropic material, the grain angle has a significant influence on its mechanical properties. The aim of this research was to perform a numerical simulation using a nonlinear finite element analysis (FEA) to obtain the compression strength of the Red Meranti (shorea spp.) timber species at an angle to the grain ranging from $12^{\circ}$ to $80^{\circ}$. The material properties needed for the analysis were obtained from clear specimen tests. To investigate the validity of the numerical results, various cross grain specimens were tested under uniaxial compressive stress. It has been shown in this study that an FEA based on the distortion energy of an orthotropic material can be used to obtain the compressive strength at proportional limit for cross grain specimens. Comparison with the experimental results showed that for a cross grain angle between $12^{\circ}$ and $80^{\circ}$ the FEA predicted the strength to be $9.4 \%$ to $33.6 \%$ lower than the experimental results. Compared to using Hankinson's formula to predict the compressive strength at a cross grain angle, using the FEA always gave a lower value, ranging from $13.2 \%$ to $30.5 \%$. Based on these results, an FEA incorporating Hill's yield criterion is a conservative method for predicting compressive strength at an angle to the grain.
\end{abstract}

Keywords: compression; FEA; grain angle; Hill's yield criterion; red meranti.

\section{$1 \quad$ Introduction}

The compressive strength is the ultimate value that can be reached before a component fails due to compression. Compressive strength at proportional limit load is an important parameter used in timber design, for example in the design of columns or posts. Similarly, the modulus of elasticity and the modulus of plasticity obtained from compressive stress-strain curves are useful for postelastic analysis, for example analysis for studying the buckling behavior of a laminated column or a laminated post.

Experimental tests and analytical research on the distortion energy criterion for timber uniaxial compression at an angle to the grain has been done previously

Received February $20^{\text {th }}, 2013,1^{\text {st }}$ Revision April $5^{\text {th }}, 2013,2^{\text {nd }}$ Revision May $2^{\text {nd }}, 2013$, Accepted for publication May $14^{\text {th }}, 2013$.

Copyright () 2013 Published by ITB Journal Publisher, ISSN: 2337-5779, DOI: 10.5614/j.eng.technol.sci.2013.45.3.2 
[1]. It proved difficult to obtain the real compression strength for specimens at an angle to the grain. In general, failure occurred not in the plane perpendicular to the load, but in the principal plane of the material.

The aim of this research was to perform a numerical simulation using a nonlinear finite element analysis (FEA) to obtain the compressive strength at an angle to the grain ranging from $12^{\circ}$ to $80^{\circ}$ for the Indonesian hardwood timber species named Red Meranti (shorea spp.). Compressive strength in this paper is defined as the strength at proportional limit and is assumed to be the same as compressive yield strength. To investigate the validity of the finite element analysis results, various cross grain specimens, as shown in Figure 1, were tested under uniaxial compressive stress.

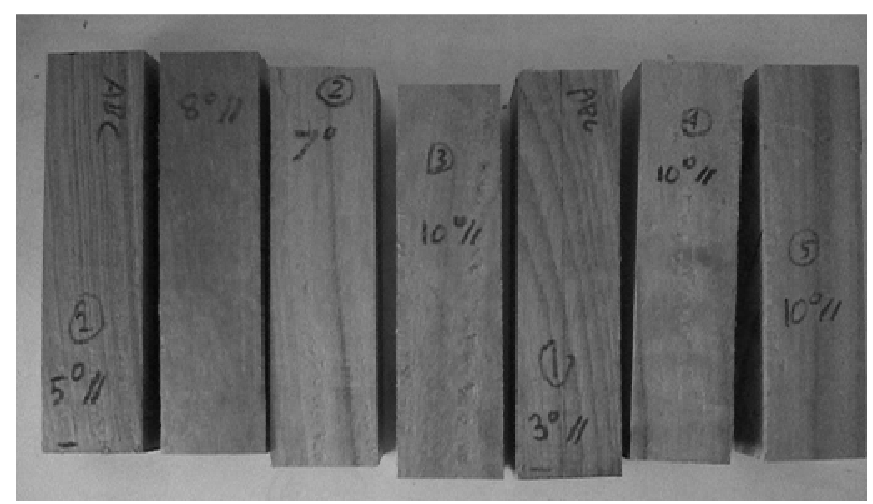

Figure 1 Examples of various cross grain specimens.

In finite element analysis, a plasticity-based constitutive material model is used to represent wood as a nonlinear orthotropic material according to the extension of the Von Mises yield criterion, called the Hill yield criterion [2-5]. The material properties needed were obtained from clear specimen tests in accordance with ASTM D143 [6].

\section{$2 \quad$ Methodology}

\subsection{Elastic Orthotropic Equation}

Wood is generally assumed to behave as an orthotropic material with three mutually perpendicular material principal axes, namely the longitudinal, radial, and tangential axes. The constitutive relation of a linear elastic orthotropic material can be described in accordance with Hooke's law [7]. The elastic modulus $(E)$ is the slope of the stress-strain curve in the elastic region. $E_{L}$ is the slope of the longitudinal-axe (parallel to the grain) stress-strain curve. $E_{R}$ is the 
slope of the radial-axe stress-strain curve. $E_{T}$ is the slope of the tangential-axe stress-strain curve. In this research, the radial and tangential axises are assumed to be equal and called perpendicular to the grain.

$$
\left\{\begin{array}{c}
\varepsilon_{L} \\
\varepsilon_{R} \\
\varepsilon_{T} \\
\gamma_{R T} \\
\gamma_{L T} \\
\gamma_{L R}
\end{array}\right\}=\left[\begin{array}{cccccc}
\frac{1}{E_{L}} & \frac{-v_{R L}}{E_{R}} & \frac{-v_{T L}}{E_{T}} & 0 & 0 & 0 \\
\frac{-v_{L R}}{E_{L}} & \frac{1}{E_{R}} & \frac{-v_{T R}}{E_{T}} & 0 & 0 & 0 \\
\frac{-v_{L T}}{E_{L}} & \frac{-v_{R T}}{E_{R}} & \frac{1}{E_{T}} & 0 & 0 & 0 \\
0 & 0 & 0 & \frac{1}{G_{R T}} & 0 & 0 \\
0 & 0 & 0 & 0 & \frac{1}{G_{L T}} & 0 \\
0 & 0 & 0 & 0 & 0 & \frac{1}{G_{L R}}
\end{array}\right]\left\{\begin{array}{c}
\sigma_{L} \\
\sigma_{R} \\
\sigma_{T} \\
\tau_{R T} \\
\tau_{L T} \\
\tau_{L R}
\end{array}\right\}
$$

The lateral strain at any point in a bar is proportional to the axial strain at that same point if the material is linearly elastic. The ratio $(v)$ of these strains is a property of the material known as Poisson's ratio [8].

$$
v=\frac{\text { lateral strain }}{\text { axial strain }}
$$

The Poisson's ratios are denoted by $v_{L R}, v_{L T}, v_{R T}, v_{R L}, v_{T L}$, and $v_{T R}$. The first letter of the subscript refers to the direction of the applied stress and the second letter to the direction of the lateral deformation. The relation between all six Poisson's ratios and all three elastic moduli are calculated using Eq. (3) [7].

$$
\begin{aligned}
& \frac{v_{R L}}{E_{R}}=\frac{v_{L R}}{E_{L}} \\
& \frac{v_{T L}}{E_{T}}=\frac{v_{L T}}{E_{L}} \\
& \frac{v_{T R}}{E_{T}}=\frac{v_{R T}}{E_{R}}
\end{aligned}
$$

The modulus of rigidity, also called shear modulus, indicates the resistance to deflection of a member caused by shear stresses. The three moduli of rigidity, 
denoted by $G_{L R}, G_{L T}$, and $G_{R T}$, are the elastic constants in the LR, LT, and RT planes, respectively. All three shear moduli are calculated using Eq. (4) [9].

$$
\begin{aligned}
& G_{L R}=\frac{E_{L} \cdot E_{R}}{E_{L} \cdot\left(1+v_{L R}\right)+E_{R} \cdot\left(1+v_{R L}\right)} \\
& G_{L T}=\frac{E_{L} \cdot E_{T}}{E_{L} \cdot\left(1+v_{L T}\right)+E_{T} \cdot\left(1+v_{T L}\right)} \\
& G_{R T}=\frac{E_{R} \cdot E_{T}}{E_{R} \cdot\left(1+v_{R T}\right)+E_{T} \cdot\left(1+v_{R T}\right)}
\end{aligned}
$$

Although the microstructure of wood is very complex, it is assumed to be homogeneous. Natural imperfections such as knots, taper, and distortions in the alignment of the grain are ignored. If a sample is cut far enough from the center of the tree so that the curvature of the growth rings can be ignored, the mechanical properties of wood may be regarded as orthotropic [7].

\subsection{Axial Load-Deformation and Stress-Strain Curves}

As seen in Figure 2(b), axial stress $\left(\sigma_{\mathrm{c} / /}\right)$ is the compressive stress in the direction parallel to the grain $[3-6,10] . \sigma_{\mathrm{c} / /}$ is the axial load $(P)$ divided by the initial cross section area of the specimen $(A)$. Axial strain $\left(\varepsilon_{\mathrm{c} / /}\right)$ is axial deformation $(\Delta)$ divided by the initial length of the specimen. The axial load vs. the axial deformation curve (Figure 2(a)) was obtained from the compression parallel to the grain test.

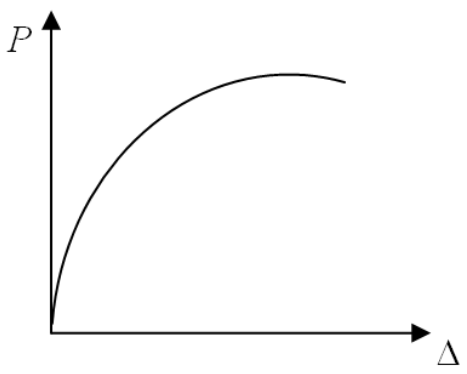

(a) Load-deformation curve

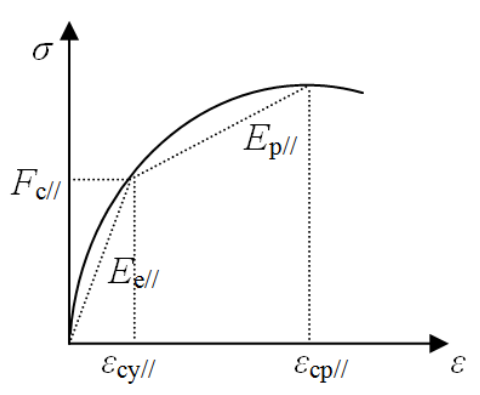

(b) Stress-strain curve

Figure 2 Compression parallel to the grain stress-strain curve idealization.

The slope of the stress-strain curve in the elastic region, as shown in Figure 2(b), is called the modulus of elasticity parallel to the grain $\left(E_{L}\right.$ or $\left.E_{e / /}\right)$. The slope of the stress-strain curve in the post-elastic region is named the modulus 
of plasticity parallel to the grain $\left(E_{p / /}\right) . F_{\mathrm{c} / /}$ is the compressive strength (proportional limit load) parallel to the grain [3-6,10].

Axial stress $\left(\sigma_{\mathrm{c}} \perp\right)$ is the compressive stress perpendicular to the grain $[3-6,10]$, as shown in Figure 3(b). $\sigma_{\llcorner} \perp$ is the load $(P)$ divided by the initial cross section area of the specimen $(A)$. Strain $\left(\varepsilon_{\mathrm{c}} \perp\right)$ is the deformation $(\Delta)$ divided by the initial length of the specimen. The load vs. deformation curve (Figure 3(a)) was obtained from the compression perpendicular to the grain test. The slope of the stress-strain curve in the elastic region is called the modulus of elasticity perpendicular to the grain $\left(E_{R}\right.$ or $E_{T}$ or $\left.E_{e} \perp\right)$. The slope of the stress-strain curve in the post-elastic region is called the modulus of plasticity perpendicular to the grain $\left(E_{p} \perp\right) . \quad F_{\mathrm{c}} \perp$ is the compressive strength (proportional limit load) perpendicular to the grain $[3-6,10]$.
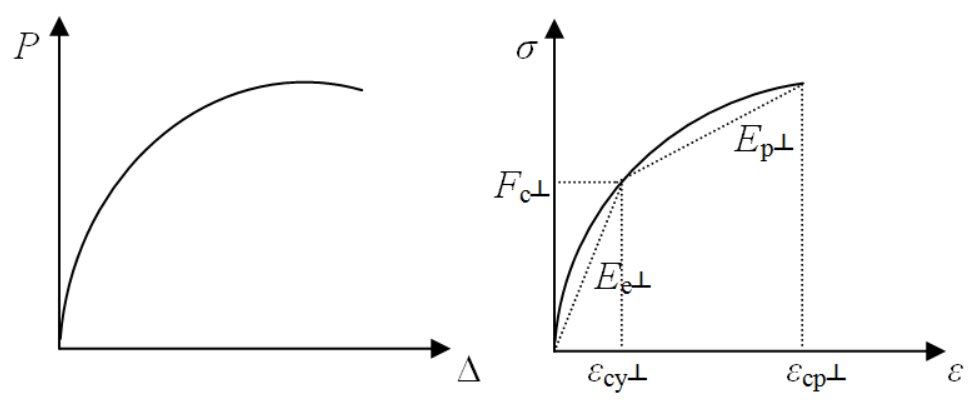

Figure 3 Compression perpendicular to the grain stress-strain curve idealization.

Shear failure in timber is one of the critical factors to be considered in the design of timber members. The shear strength is denote as $F_{v / /}$, stress is assumed to be distributed uniformly, and the shear strength [6] is calculated as,

$$
F_{v}=\frac{P_{\max }}{A}
$$

where $P_{\max }$ is the maximum load and $A$ is the area of shear plane. Details of the shear specimen can be seen in Figure 9.

\subsection{Plastic-Orthotropic Material Model}

Nonlinear inelastic orthotropic materials can be modeled using Hill's yield criterion [2-5,11]. This criterion is an extension of the Von Mises yield criterion. According to this criterion, failure occurs if, 


$$
\begin{aligned}
f\left(\sigma_{i j}\right)= & F\left(\sigma_{b b}-\sigma_{c c}\right)^{2}+G\left(\sigma_{c c}-\sigma_{a a}\right)^{2} \\
& +H\left(\sigma_{a a}-\sigma_{b b}\right)^{2}+2 L \sigma_{a b}^{2}+2 M \sigma_{a c}^{2}+2 N \sigma_{b c}^{2}-1=0
\end{aligned}
$$

where,

$$
\begin{aligned}
& F=\frac{1}{2}\left(\frac{1}{Y^{2}}+\frac{1}{Z^{2}}-\frac{1}{X^{2}}\right) \\
& G=\frac{1}{2}\left(\frac{1}{Z^{2}}+\frac{1}{X^{2}}-\frac{1}{Y^{2}}\right) \\
& H=\frac{1}{2}\left(\frac{1}{X^{2}}+\frac{1}{Y^{2}}-\frac{1}{Z^{2}}\right) \\
& L=\frac{1}{2 Y_{a b}^{2}} \\
& M=\frac{1}{2 Y_{a c}^{2}} \\
& N=\frac{1}{2 Y_{b c}^{2}}
\end{aligned}
$$

where $\mathrm{a}, \mathrm{b}, \mathrm{c}$ are the three main directions of the material. $X, Y, Z$ are yield stresses in the direction of a, b, c, and $Y_{\mathrm{ab}}, Y_{\mathrm{ac}}, Y_{\mathrm{bc}}$ are yield stresses for pure shear at plane $(a, b),(a, c)$, and $(b, c)$.

The accumulated effective plastic strain $\bar{\varepsilon}_{a}^{P}$ is defined using the principle of the equivalence of plastic work,

$$
d W^{P}=\bar{\sigma}_{a} d \bar{\varepsilon}_{a}^{P}
$$

In general, the accumulated effective plastic strain is not equal to the uniaxial plastic strain [11]. The hardening rule is defined in terms of the relationship between the yield stress and the accumulated effective plastic strain. The plastic modulus is defined as,

$$
E_{u}^{P}=\sqrt{\frac{1}{2}\left\{\frac{1}{3}\left(E_{a}^{P^{2}}+E_{b}^{P^{2}}+E_{c}^{P^{2}}\right)+E_{a b}^{P^{2}}+E_{a c}^{P^{2}}+E_{b c}^{P^{2}}\right\}}
$$

where, 


$$
\begin{gathered}
E_{i}^{P}=\frac{E_{i} E_{i}^{T}}{E_{i}-E_{i}^{T}} \quad i=a, b, c \\
E_{i j}^{P}=\frac{E_{i j} E_{i j}^{T}}{E_{i j}-E_{i j}^{T}} \quad i j=a b, a c, b c
\end{gathered}
$$

$E_{a}^{T}, E_{b}^{T}, E_{c}^{T}$ are independent moduli for the a, b, c directions and for the $(\mathrm{a}, \mathrm{b})$, $(\mathrm{a}, \mathrm{c}),(\mathrm{b}, \mathrm{c})$ planes. Note that orthotropic proportional hardening reduces to isotropic hardening for the appropriate values of the elastic and tangent moduli. The effective-stress-function algorithm is used to calculate stresses and plastic strains when plasticity occurs. The initial yield stress $\left(\sigma_{y}\right)$ is entered by direct specification of the yield stresses $X, Y, Z, Y_{a b}, Y_{a c}, Y_{b c}$, then the following formula is applied,

$$
\sigma_{y}^{2}=\frac{1}{2}\left\{\frac{1}{3}\left(X^{2}+Y^{2}+Z^{2}\right)+Y_{a b}^{2}+Y_{a c}^{2}+Y_{b c}^{2}\right\}
$$

\subsection{Hankinson's Formula for Uniaxial Stress with Cross Grain}

Because of the complexity of failure phenomena in timber, predictions using basic theory have yet to be fully developed. Consequently, empirical methods have been used to study failure phenomena in timber [12]. For cases of uniaxial compressive stress in orthotropic materials with cross grain $\theta$, as shown in Figure 4, many codes, for example NDS [13], use the empirical Hankinson's formula,

$$
F_{\theta}=\frac{F_{c / /} F_{c \perp}}{F_{c / /} \sin ^{2} \theta+F_{c \perp} \cos ^{2} \theta}
$$

where $F_{\theta}=$ compressive strength at an angle to the grain.

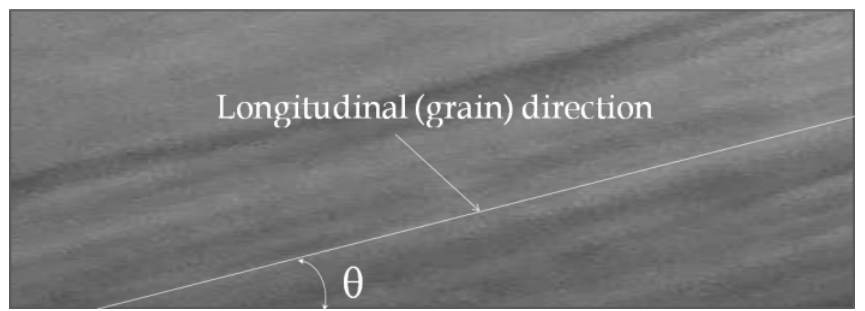

Figure 4 An orthotropic material with cross grain $\theta[14,15]$. 
Experimental evidence establishes the validity of Hankinson's formula for the compression strength of timber. Figure 5 shows a representation of the compression strength-grain angle relationship from Hankinson's formula and experimental values [12].

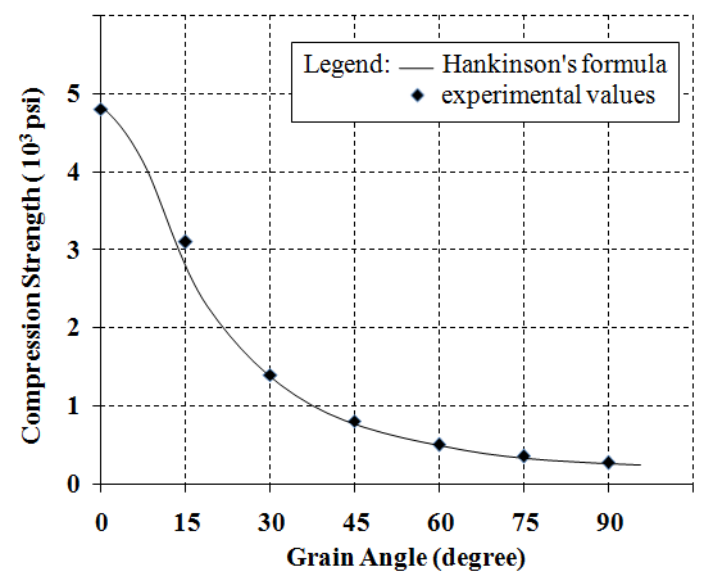

Figure 5 Representation of the compression strength-grain angle relationship from Hankinson's formula [12].

\subsection{Nonlinear Finite Element Method}

Numerical simulation to predict the yield stress for compression at an angle to the grain can be done using a software application named ADINA, based on nonlinear finite element analysis (FEA) [16]. Nonlinear stress-strain curves for all three principal axes of the orthotropic material are modeled in accordance with Hill's yield criterion. The hardening rule is defined in terms of the relationship between the yield stress and the accumulated effective plastic strain.

The three-dimensional solid element is a variable 10-node isoparametric element applicable to general 3-D analysis. A numerical model of the specimen is modeled using one of the 3-D elements called a tetrahedral element with ten nodes as shown in Figure 6.

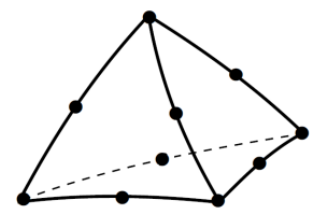

Figure 6 Tetrahedral element with ten nodes [16]. 
In nonlinear static analysis, the equilibrium Eq. [11] to be solved are,

$$
{ }^{t+\Delta t} R-{ }^{t+\Delta t} F=0
$$

where ${ }^{t+\Delta t} R$ is the vector of externally applied nodal loads at time (load) step $t+\Delta t$, and ${ }^{t+\Delta t} F$ is the force vector equivalent (in the virtual work sense) to the element stresses at time $t+\Delta t$.

The load-displacement-control (LDC) method (or arc length method) can be used to solve the nonlinear equilibrium path of a model until its collapse. The LDC method can only be used in a nonlinear static analysis in which there are no temperature, strain-rate, pipe internal pressure or creep effects. The LDC method can be used in contact problems [11]. The equations employed in the equilibrium iterations are,

$$
\begin{aligned}
& { }^{t+\Delta t} K^{(i-1)} \Delta U^{(i)}=\left({ }^{t+\Delta t} \lambda^{(i-1)}+\Delta \lambda^{(i)}\right) R+R_{P}-{ }^{t+\Delta t} F^{(i-1)} \\
& { }^{t+\Delta t} U^{(i)}={ }^{t+\Delta t} U^{(i-1)}+\Delta U^{(i)} \\
& f\left(\Delta \lambda^{(i)}, \Delta U^{(i)}\right)=0
\end{aligned}
$$

where ${ }^{t+\Delta t} K^{(i-1)}$ is the tangent stiffness matrix at the end of iteration $(i-1)$ at time $t+\Delta t, R$ is the constant reference load vector, $R_{P}$ is the load vector from the previous solution run, ${ }^{t+\Delta t} \lambda^{(i-1)}$ is the load scaling factor (used on $R$ ) at the end of iteration $(i-1)$ at time $t+\Delta t$, and $\Delta \lambda^{(i)}$ is the increment in the load scaling factor in iteration $(i)$.

The equation $f=0$ is used to constrain the length of the load step. Usually, the constant spherical arc length constraint method is used, and the constant increment of the external work method is used if the arc length method has difficulty to converge.

\subsection{Determining the Yield Point}

The yield point indicates when plastic deformation begins. Material ductility is an indicator of how much plastic deformation the material can undergo without significant loss of strength. The calculated initial stiffness was between $10 \%$ and $40 \%$ of the peak load. A straight line between $40 \%$ and $90 \%$ of the peak load and a straight-line tangent to the load-displacement curve, parallel to the $40 \%$ and $90 \%$ secant line, were determined [17]. This last line represents the immediate post-elastic zone before reaching the peak load. The point of intersection between the initial stiffness with this new tangent was projected 
horizontally towards the load-displacement curve in order to obtain the respective yield point displacements as shown in Figure 7. This method was used to calculate the yield stress $\left(F_{c}\right)$, where $F_{c}$ is the axial load $(P)$ divided by the initial cross section area of the specimen $(A)$. The $P-\Delta$ curves are results obtained from the experimental compression tests.

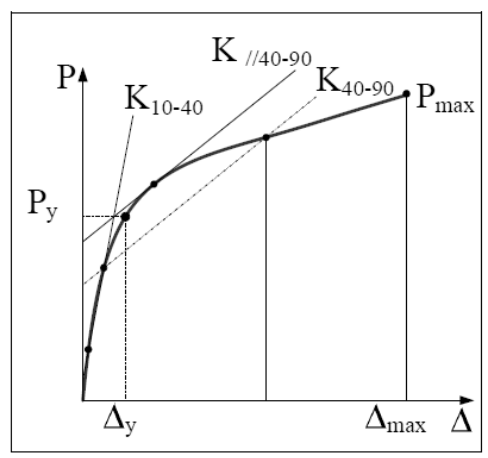

Figure 7 Yasumura and Kawai yield point method [17].

\section{$3 \quad$ Results and Discussion}

For the experimental tests, a universal testing machine was used to load each specimen. The test setup for testing the compressive strength parallel to the grain is shown in Figure 8(a); the Poisson's ratios were also obtained from these tests. The test setup for testing the compressive strength perpendicular to the grain is shown in Figure 8(b). The output obtained from both tests was the relationship between the axial load and the axial displacement. This relationship was then converted to the relationship between the axial stress and the axial displacement. The test setup for testing the shear strength parallel to the grain is shown in Figure 9. The output obtained from this test was load $(P)$, which was then converted to shear stress using Eq. (5). The maximum load $\left(P_{\max }\right)$ produced the shear strength.

The loading displacement was controlled with a displacement rate of 0.6 $\mathrm{mm} /$ minute (both compression parallel to the grain and shear tests) and 0.305 $\mathrm{mm} /$ minute (compression perpendicular to the grain). The rate was so slow that the dynamic effects could be neglected. The loading was terminated when the specimen showed significant failure.

Each specimen was weighed to obtain its density. The moisture content of each specimen after being air-dried was measured using a Lignomat digital moisture tester. Table 1 shows the specific gravity and moisture content of the Red Meranti specimens tested. 
Table 1 Physical properties of Red Meranti (number of specimens = 21).

\begin{tabular}{lc}
\hline \multicolumn{1}{c}{ Description } & Value \\
\hline Average of Specific Gravity & 0.51 \\
Coefficient of variation $(\mathrm{CoV})(\%)$ & 13.12 \\
Moisture Content $(\%)$ & 15.14 \\
\hline
\end{tabular}

Specimen dimensions for compression parallel to the grain tests $\left(\theta=0^{\circ}\right)$ were $50 \times 50 \times 200 \mathrm{~mm}$ (see Figure 8(a)). Specimen dimensions for perpendicular to the grain tests $\left(\theta=90^{\circ}\right)$ were $50 \times 50 \times 150 \mathrm{~mm}$ (see Figure 8(b)). Specimen dimensions for the shear tests were 60 × 50 × $50 \mathrm{~mm}$ (see Figure 9). These dimensions conform to the ASTM D143 [6]. Each test used 9 (nine) specimens.

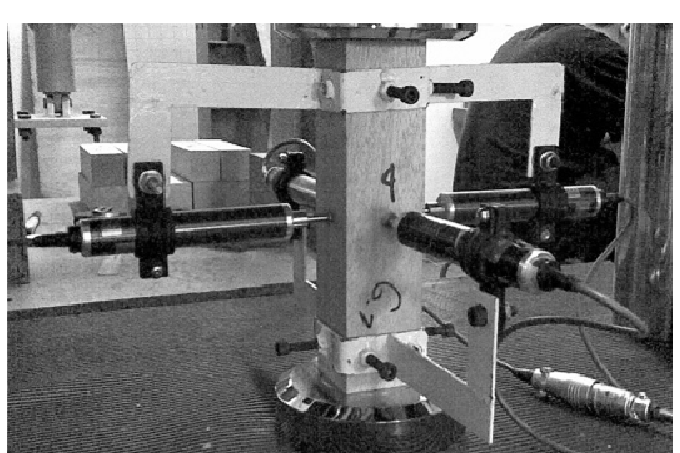

(a) Parallel to the grain.

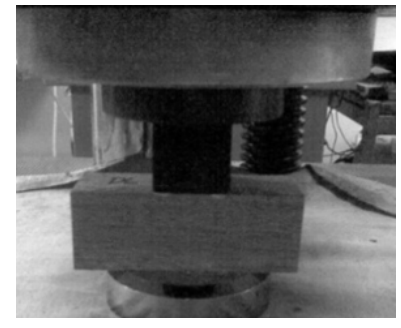

(b) Perpendicular to the grain.

Figure 8 Test setup for uniaxial compression testing.

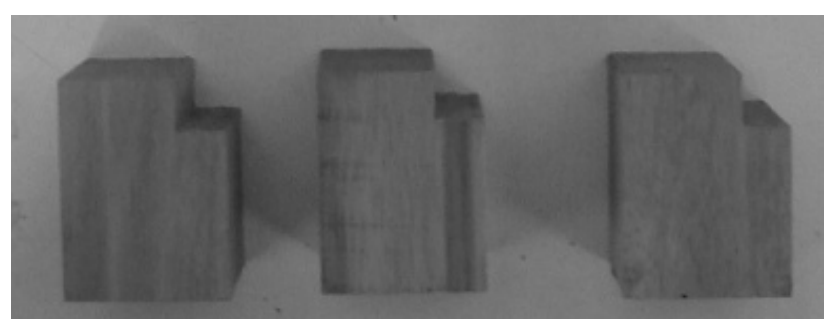

Figure 9 Specimens for shear testing.

Results obtained from the experimental tests, the $P-\Delta$ curves as a model for compression parallel to the grain, can be seen in Figure 10(a), while Figure 10(b) shows the axial stress-strain curves for compression parallel to the grain $\left(\theta=0^{\circ}\right)$. MM1 through MM9 are legends for each specimen test. 


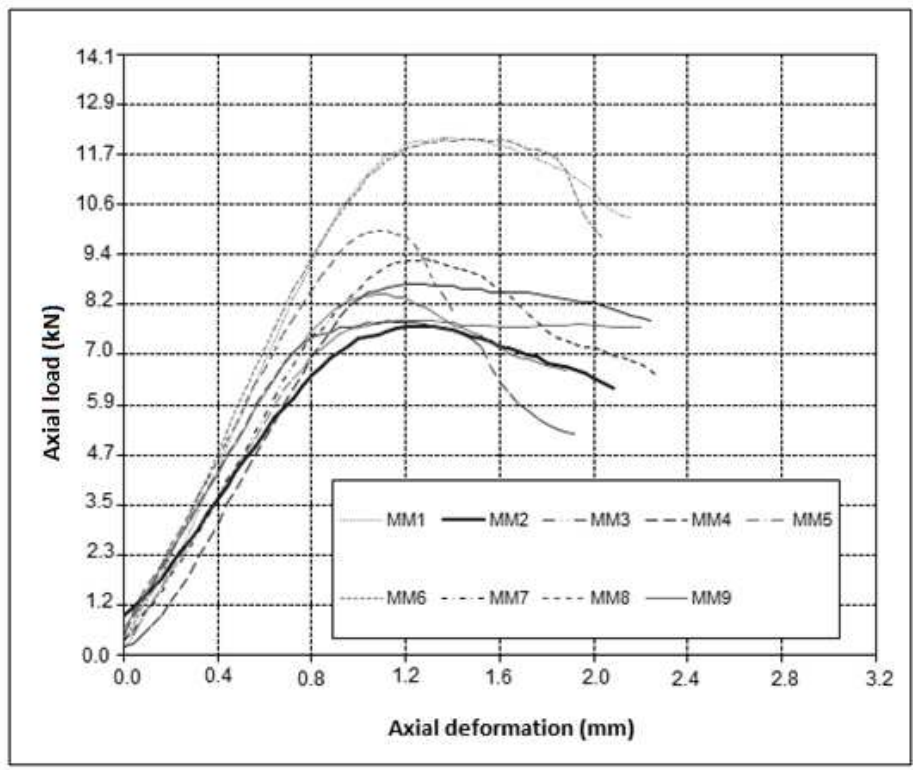

(a) The axial load vs. axial displacement curves.

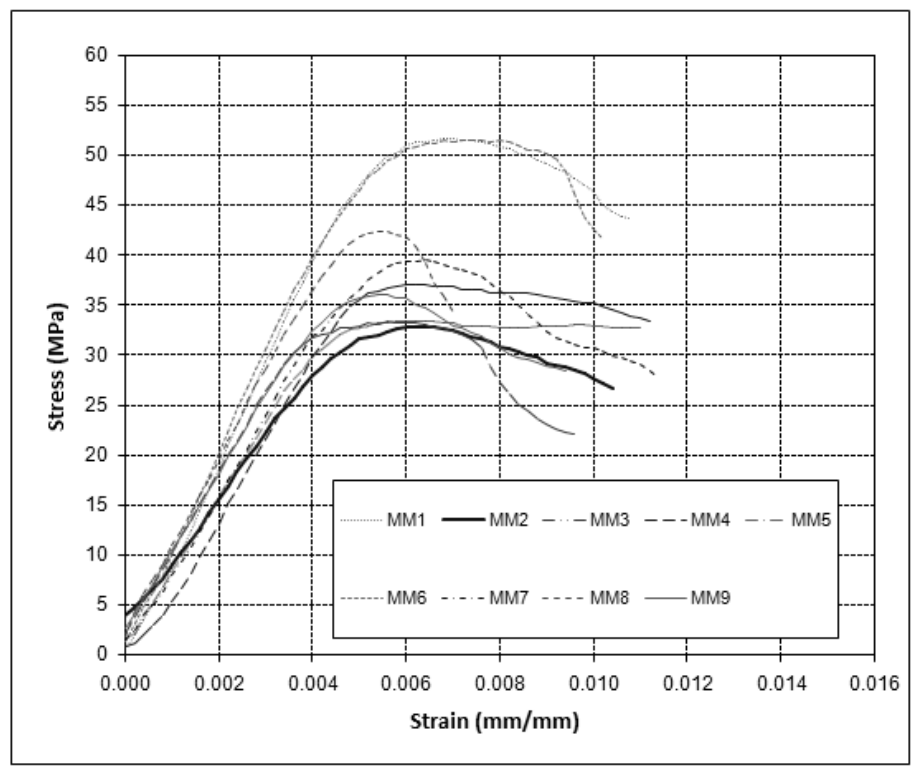

(b) The compression parallel to the grain stress vs. strain curves.

Figure 10 Results obtained from experimental tests of compression parallel to the grain $\left(\theta=0^{\circ}\right)$. 
The Yasumura and Kawai yield point method was used to obtain the value of $F_{c / /}$ and $F_{c} \perp$. The results can be seen in Table 2, in which Eq. (5) was used to obtain the value of $F_{\mathrm{v} / / .}$ As shown in Table 2, the compressive strength parallel to the grain was the largest among the three strengths and could be as high as forty times the compressive strength perpendicular to the grain. Compressive strength perpendicular to the grain was the lowest among the three.

Table 2 Compressive parallel to the grain $\left(F_{c / /}\right)$, compressive perpendicular to the grain $\left(F_{c} \perp\right)$, and shear strengths $\left(F_{v / /}\right)$ obtained from tests [1].

\begin{tabular}{ccc}
\hline Strength & $\begin{array}{c}\text { Value } \\
(\mathbf{M p a})\end{array}$ & $\begin{array}{c}\text { Coefficient of Variation } \\
(\boldsymbol{\%})\end{array}$ \\
\hline$F_{c / /}\left(\theta=0^{\circ}\right)$ & 33.67 & 17.82 \\
$F_{c \perp}\left(\theta=90^{\circ}\right)$ & 7.17 & 15.69 \\
$F_{v / /}$ & 7.55 & 5.77 \\
\hline
\end{tabular}

The elastic modulus obtained from the clear specimen test for the longitudinal direction $\left(E_{\mathrm{e} / /}\right)$ was $8261.46 \mathrm{MPa}$, while for the radial and the tangential direction $\left(E_{\mathrm{e}} \perp\right)$ it was $688.78 \mathrm{MPa}$. The bilinear plastic modulus for the longitudinal direction $\left(E_{\mathrm{p} / /}\right)$ was $2804.83 \mathrm{MPa}$, while for the radial and the tangential direction $\left(E_{\mathrm{p}} \perp\right)$ it was $86.79 \mathrm{MPa}$. The three Poisson's ratios were $v_{\mathrm{LR}}$ $=0.014, v_{\mathrm{LT}}=0.027$, and $v_{\mathrm{RT}}=0.247$. The three shear moduli were calculated using Eq. (4); the results were $G_{\mathrm{LR}}=548.15 \mathrm{MPa}, G_{\mathrm{LT}}=488.63 \mathrm{MPa}$, and $G_{\mathrm{RT}}$ $=276.25 \mathrm{MPa}$.

The specimens for grain angles of $12^{\circ}, 60^{\circ}$, and $80^{\circ}$ were all subjected to the compression parallel to the grain test; details of several of the specimens can be seen in Figure 1. Table 3 shows a comparison of the results for the compression strengths at grain angles of $12^{\circ}, 60^{\circ}$, and $80^{\circ}$ obtained from the experimental tests, Hankinson's formula, and FEA.

Table 3 Compressive strength at grain angles of $12^{\circ}, 60^{\circ}$, and $80^{\circ}$ obtained from Hankinson's formula, experimental tests, and FEA.

\begin{tabular}{cccc}
\hline $\begin{array}{c}\text { Angle } \\
\boldsymbol{\theta}\left({ }^{\mathbf{}}\right)\end{array}$ & $\begin{array}{c}\text { Hankinson's } \\
\text { formula }(\mathbf{M P a})\end{array}$ & $\begin{array}{c}\text { Experimental tests* } \\
(\mathbf{M p a})\end{array}$ & $\begin{array}{c}\text { FEA } \\
(\mathbf{M P a})\end{array}$ \\
\hline 12 & 29.03 & 27.82 & 25.20 \\
60 & 8.92 & 8.52 & 6.20 \\
80 & 7.34 & 7.68 & 5.10 \\
\hline
\end{tabular}

*average value

As shown in Table 3, the experimental compressive strength at an angle to the grain was obtained from the stress-strain curves, where the yield point was calculated using the Yasumura and Kawai yield point method [17]. The FEAbased compressive strength at an angle to the grain was obtained from the value of $\sigma_{z z}$ when failure occured. Hankinson's compressive strength at an angle to the grain was calculated using Eq. (12). 
According to Hill's yield criterion (Eq. (6)), failure occurs if $f\left(\sigma_{\mathrm{ij}}\right)=0$, with $X$ and $Y$ as compression strength perpendicular to the grain $\left(F_{c / l}\right), Z$ as compression strength parallel to the grain $\left(F_{c} \perp\right)$, and $Y_{a b}, Y_{a c}$, and $Y_{b c}$ as shear strength. The shear strength $\left(F_{v / / /}\right)$ for all directions $\left(Y_{a b}, Y_{a c}\right.$, and $\left.Y_{b c}\right)$ was obtained from the shear tests. Step by step details of the calculation of $f\left(\sigma_{\mathrm{ij}}\right)$ obtained from the FEA, as a model for the specimen with a grain angle of $12^{\circ}$, can be seen in Table 4 . As shown in the table, the values of $f\left(\sigma_{\mathrm{ij}}\right)$ for step 1 through step 7 are all negative, indicating that failure did not occur. At time step 8 , failure occurs when $f\left(\sigma_{\mathrm{ij}}\right)=0.71$.

Table 4 Stresses obtained from numerical simulation, as a model for the specimen with a grain angle of $12^{\circ}$.

\begin{tabular}{ccccccccc}
\hline $\begin{array}{c}\text { Time } \\
\text { step }\end{array}$ & $\begin{array}{c}\boldsymbol{\sigma}_{\mathbf{X X}} \\
(\mathbf{M P a})\end{array}$ & $\begin{array}{c}\boldsymbol{\sigma}_{\mathbf{Y Y}} \\
(\mathbf{M P a})\end{array}$ & $\begin{array}{c}\boldsymbol{\sigma}_{\mathbf{Z Z}} \\
(\mathbf{M P a})\end{array}$ & $\begin{array}{c}\boldsymbol{\sigma}_{\mathbf{X Y}} \\
(\mathbf{M P a})\end{array}$ & $\begin{array}{c}\boldsymbol{\sigma}_{\mathbf{X Z}} \\
(\mathbf{M P a})\end{array}$ & $\begin{array}{c}\boldsymbol{\sigma}_{\mathbf{Y Z}} \\
(\mathbf{M P a})\end{array}$ & $\begin{array}{c}\boldsymbol{\sigma}_{\text {eff }} \\
(\mathbf{M P a})\end{array}$ & $\boldsymbol{f}\left(\boldsymbol{\sigma}_{\mathbf{i j}}\right)$ \\
\hline 1 & 0.71 & 0.14 & -0.23 & -0.31 & -0.42 & 0.04 & 1.04 & -0.99 \\
2 & 1.43 & 0.28 & -0.46 & -0.63 & -0.83 & 0.08 & 2.09 & -0.95 \\
3 & 2.13 & 0.44 & -0.72 & -0.97 & -1.28 & 0.12 & 3.17 & -0.90 \\
4 & 2.93 & 0.74 & -1.06 & -1.44 & -1.98 & 0.17 & 4.58 & -0.79 \\
5 & 4.32 & 1.76 & -1.97 & -2.76 & -4.05 & 0.38 & 8.14 & -0.43 \\
6 & 3.39 & 3.05 & 0.75 & -4.18 & -5.57 & 2.17 & 9.27 & -0.06 \\
7 & -11.98 & -11.70 & -16.20 & -4.71 & -5.86 & 2.15 & 10.53 & -0.08 \\
8 & -19.45 & -24.50 & -25.20 & -5.07 & -6.21 & 1.98 & 11.49 & 0.71 \\
9 & -23.31 & -28.52 & -32.00 & -5.40 & -6.58 & 2.14 & 13.15 & 0.92 \\
10 & -24.85 & -30.19 & -34.06 & -5.73 & -6.97 & 2.34 & 13.94 & 1.11 \\
11 & -25.49 & -30.93 & -35.19 & -6.04 & -7.37 & 2.55 & 14.73 & 1.32 \\
12 & -25.75 & -31.30 & -35.95 & -6.36 & -7.79 & 2.75 & 15.53 & 1.55 \\
13 & -25.81 & -31.50 & -36.55 & -6.67 & -8.20 & 2.95 & 16.35 & 1.80 \\
14 & -25.75 & -31.61 & -37.05 & -7.00 & -8.63 & 3.13 & 17.19 & 2.06 \\
15 & -25.61 & -31.64 & -37.49 & -7.32 & -9.05 & 3.32 & 18.04 & 2.34 \\
16 & -25.42 & -31.63 & -37.87 & -7.64 & -9.49 & 3.49 & 18.90 & 2.63 \\
17 & -25.21 & -31.56 & -38.21 & -7.96 & -9.93 & 3.67 & 19.74 & 2.94 \\
18 & -24.97 & -31.45 & -38.48 & -8.28 & -10.37 & 3.85 & 20.58 & 3.25 \\
\hline
\end{tabular}

Figure 11 shows the effective stress contour obtained from the FEM simulation for the specimen model with a grain angle of $12^{\circ}$ (note that the z-axis is in the axial direction).

Figure 12, Figure 13, and Figure 14 show both experimental-test and FEAsimulation results obtained from the specimens with grain angles of $12^{\circ}, 60^{\circ}$, and $80^{\circ}$, respectively. The FEA simulation results indicate that the compressive strengths are always lower compared to the experimental test results, with a difference of $9.4 \%$ to $33.6 \%$. A possible source of these differences are the 
mechanical properties of the material used in the FEA that might differ from those of the specimens. It should be noted that wood is a natural material whose mechanical properties vary from species to species, from tree to tree, and even from one spot in a lumber to another. Compared to Hankinson's formula, the compressive strength at an angle to the grain predicted using the FEA was always lower, ranging from $13.2 \%$ to $30.5 \%$.

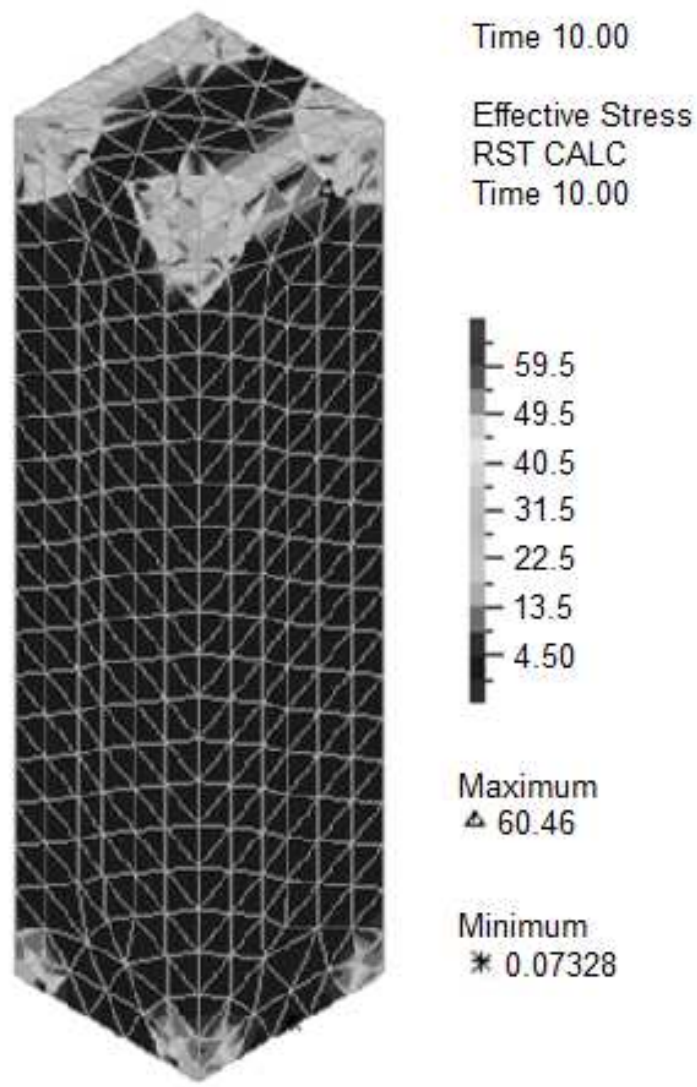

Figure 11 Numerical simulation for a grain angle of $12^{\circ}$.

As shown in Figure 12, Figure 13, and Figure 14, MM is the legend for each specimen's test result, while FEA is the legend for the FEA result. 


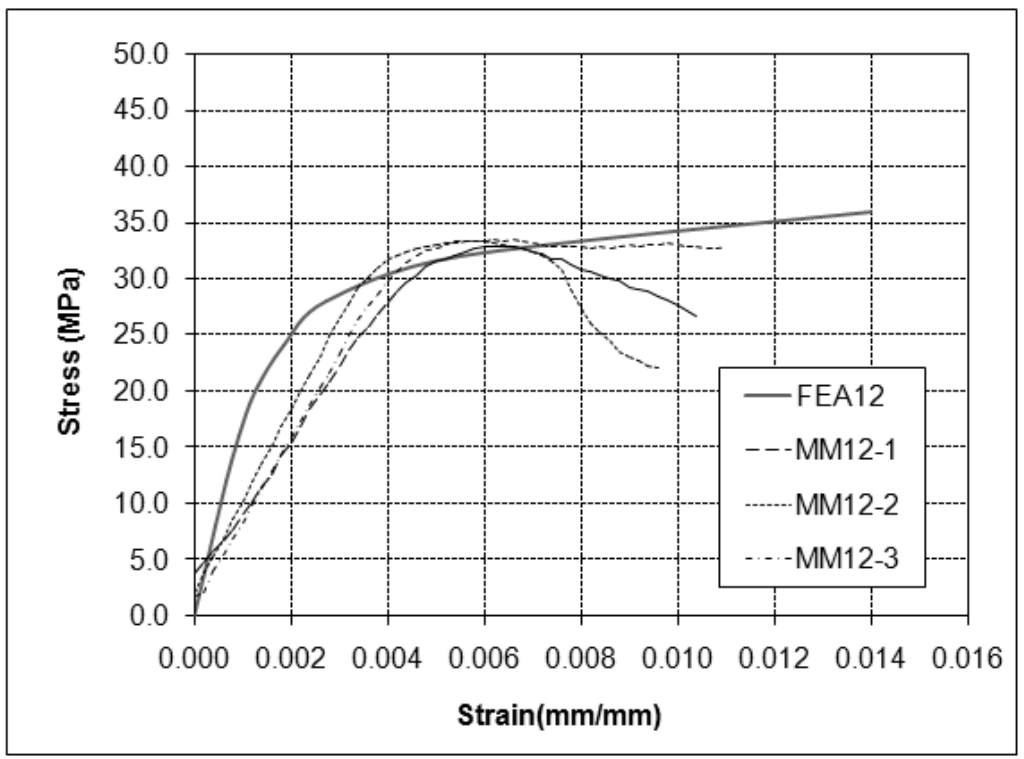

Figure 12 Comparison of stress-strain curves for specimens with a grain angle of $12^{\circ}$.

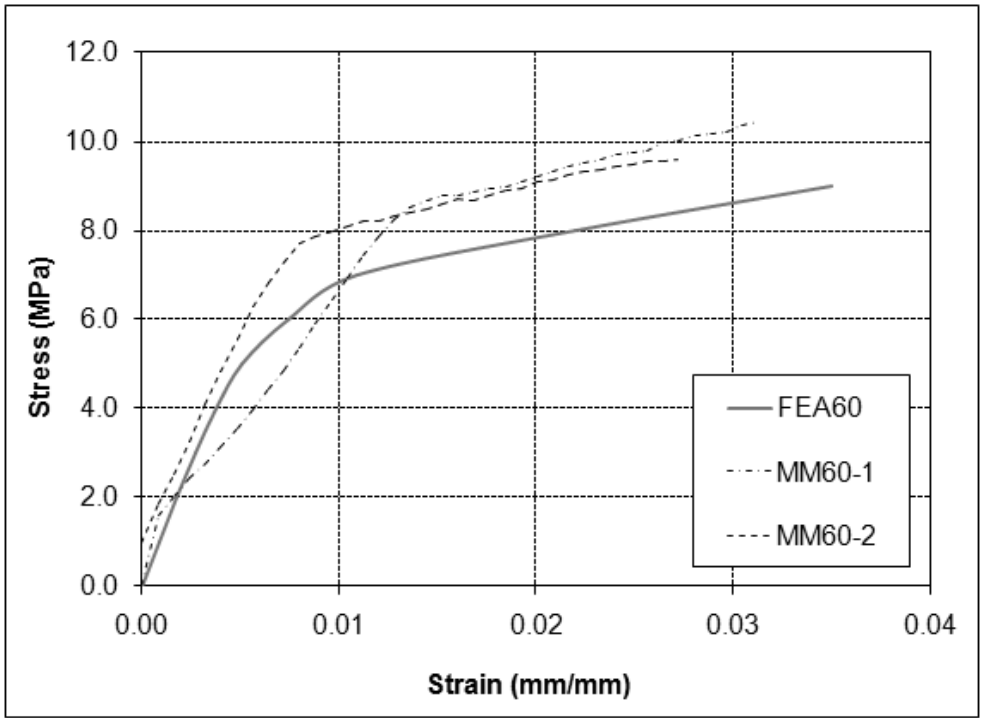

Figure 13 Comparison of stress-strain curves for specimens with an angle $60^{\circ}$. 


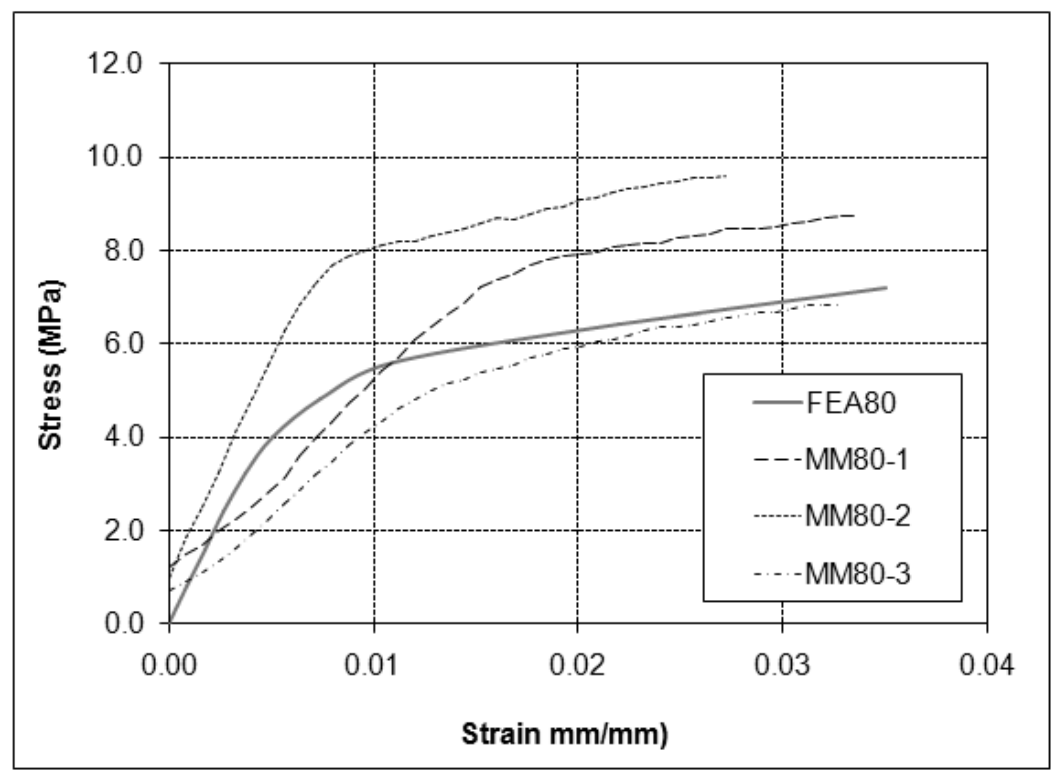

Figure 14 Comparison of stress-strain curves for specimens with an angle of $80^{\circ}$.

\section{Conclusion}

It has been shown in this study that a finite element analysis (FEA) based on a distortion energy criterion in an orthotropic material can be used to obtain the compressive strength at proportional limit for cross grain specimens. Comparison with experimental results shows that for a cross grain angle between $12^{\circ}$ to $80^{\circ}$ the FEA predicts a strength that is $9.4 \%$ to $33.6 \%$ lower than the experimental results. Compared to Hankinson's formula, the compressive strength at an angle to the grain predicted using the FEA was always lower, ranging from $13.2 \%$ to $30.5 \%$. Based on these results, an FEA incorporating Hill's yield criterion is a conservative method for predicting compressive strength at an angle to the grain.

\section{Acknowledgements}

The authors gratefully acknowledge the financial support of Maranatha Christian University, and the laboratory and software support of Parahyangan Catholic University. 


\section{References}

[1] Pranata, Y.A. \& Suryoatmono, B., Distortion Energy Criterion for Timber Uniaxial Compression Mechanical Properties (In Indonesian), Dinamika Teknik Sipil, 12(2), pp. 108-114, May 2012.

[2] Chen, W.F. \& Han, D.J., Plasticity for Structural Engineers, Ross Publishing. Lauderdale, FL, USA, 2007.

[3] Jeong, G.Y., Park, M.J., Park, J.S. \& Hwang, K.H., Predicting LoadCarrying Capacity of Dovetail Connections Using The Stochastic Finite Element Method, Journal of Wood and Fiber Science, 44(4), pp. 430-439, 2012.

[4] Kharouf, N., McClure, G. \& Smith, I., Elasto-plastic Modeling of Wood Bolted Connections, Journal of Computers and Structures, 81(8-11), pp. 747-754, 2003.

[5] Kharouf, N., McClure, G. \& Smith, I., Post-elastic Behavior of Singleand Double-Bolt Timber Connections, ASCE Journal of Structural Engineering, 131(1), 2005.

[6] American Society for Testing and Materials, Annual Book of ASTM Standards 2008 - Section 4 Volume 04.10 Wood, American Society for Testing and Materials, 2008.

[7] Persson, K., Micromechanical Modeling of Wood and Fibre Properties, Unpublished, Department of Mechanics and Materials, Lund University, Sweden, 2000.

[8] Gere, J.M., Mechanics of Materials, $6^{\text {th }}$ edition, Brooks/Cole, 2004.

[9] Karlinasari, L., Surjokusumo, S., Nugroho, N., Hadi, Y.S. \& Suryoatmono, B., Bending Strength Prediction of Wood Beam Constructed from Small Specimens, $15^{\text {th }}$ International Symposium Nondestructive of Wood, Duluth, Minnesota, USA, 10-12 September 2007.

[10] Tjondro, J.A., Suryoatmono, B. \& Imran, I. Non-linear Compression Stress-strain Curve Model for Hardwood, Proceedings of The 1st International Symposium of The Indonesian Wood Research Society, 2-3 November 2009.

[11] Kojić, M. \& Bathe, K.J., Inelastic Analysis of Solids and Structures, Springer-Verlag, 2003.

[12] Bodig, J. \& Jayne, B.A. Mechanics of Wood and Wood Composites, Krieger Publishing Company, Malabar, Florida, USA.

[13] National Design Specification (NDS) for Wood Construction with Commentary and Supplement Design Values for Wood Construction 2012 Edition, American Forest \& Paper Association, Inc. 2012.

[14] Suryoatmono, B. \& Pranata, Y.A., An Alternative to Hankinson's Formula for Uniaxial Tension at an Angle to The Grain, Proceedings of World Conference on Timber Engineering, Auckland, New Zealand, 1619 July 2012. 
[15] Suryoatmono, B. \& Pranata, Y.A., Distortion Energy Criterion for Uniaxial Tension at an Angle to The Grain, Society of Wood Science and Technology 2011 International Annual Convention, Portland, Oregon, USA, 22 June 2011.

[16] ADINA R\&D, Inc., ADINA version 8.6.2 Theory and Modeling Guide Volume 1, ADINA R\&D, Inc., 71 Elton Ave., Watertown, MA 02472, USA, 2009.

[17] Munoz, W., Mohammad, M., Salenikovich, A. \& Quenneville, P., Determination of Yield Point and Ductility of Timber Assemblies: In Search for a Harmonized Approach, Engineered Wood Products Association, 2010. 